\title{
Building Bridges for School Improvement: A Model for Sustainable University-School Partnerships
}

\author{
Wendy Barber ${ }^{1}$, Suzanne de Castell ${ }^{2}$, Janette Hughes ${ }^{3}$ \\ University of Ontario Institute of Technology $y^{1,2,3}$
}

\begin{abstract}
Public education in the $21 \mathrm{C}$ presents high needs schools with significant challenges and often unequal access to digital technologies. To address these concerns and build bridges across this digital divide, our research team conducted a one-year pilot project to develop a sustainable university-school partnership between our faculty of education and two local high needs elementary schools. The project is examined through several lenses, including the importance of university-school partnerships, advantages and challenges of the project, sustainability, leadership in high needs schools, school improvement factors, the role of community involvement and the effect of comprehensive school health on student achievement. In this article, we describe the initial formation of a partnership between the university and two schools identified as high needs by Educational Quality and Accountability Office scores, as well as low SES and demographics indicating low levels of educational aspiration and achievement. University professors, administrators, classroom teachers, students and preservice teacher candidates, worked collaboratively to lay the groundwork for a research-based and sustainable partnership by bringing the resources, strengths, skills and expertise of the schools and the faculty of education directly to bear on the "digital divide" experienced in these schools and to provide collaborative support to improve student achievement.
\end{abstract}

\section{Introduction}

This paper described a project undertaken from a conviction that recent significant pressures on public education might be relieved considerably by university faculties of education and K-12 schools creating strategic and sustainable, meaningful partnerships. The challenges faced by both these institutions are numerous, including, but not limited to, financial constraints, lack of professional development, restrictive provincial regulations, sub-optimal academic achievement across the education sector, inequitable access to resources, limited expertise in technological skills and, ironically enough given these institutions' primary purposes, lack of formal or informal knowledge-sharing. Institutional missions vary, but this project is premised on the significance of what they share.

While schools and boards of education face financial pressures likely to reduce professional development programming for teachers, university faculties of education confront deep funding cuts to initial teacher education likely to increase their graduates' need for them. With university faculties of education budgets slashed by a third, they are struggling to find creative and productive ways to maintain high quality teacher education---and indeed to improve upon it in ways specified, but not funded, by the government-notably competence and confidence with digital tools and pedagogies. These converging needs and shared conditions appear to offer an opportunity for highly productive reciprocal knowledge- and resource- sharing between universities and schools. While classroom teachers need support, with increasing numbers of high needs students, diverse cultures, languages and economic needs [13], teacher candidates (TCs) need opportunities to become aware of the specific challenges they may face in high needs schools. Further, academics have the opportunity to gain a fuller grasp of the specific conditions and realities in these schools, thereby enabling them to better align theory with the practical 'lived actualities' [19] and the day to day realities of schools. Although it is important to acknowledge that boards of education often do their utmost to support teachers, they still face significant and mounting challenges (both time and money) to support teacher development.

University faculties of education face similar issues as they continually make efforts to increase theory to practice connections and to make research-based best practices available to both pre-service and in-service teachers. As such, both institutions would benefit greatly from a solid university-school partnership. In this model of partnership, teacher candidates and practicing teachers work collaboratively together with university researchers and board administrators to create a context within which learning is shared. 
Although researchers and teachers acknowledge that these places are changing and have changed and need to change more, often we still act in silos and talk past each other. This model for partnership, based on developing mutually beneficial and respectful relationships that honour the expertise of all partners, (both experiential and theoretical), has the potential to create significant and sustainable change.

Baker reveals that there are several necessary conditions required for forming and sustaining successful university-school partnerships. He states that the seven clusters of attributes found across the literature that are indicative of successful partnerships include:

- Finding a clear focus on the common purpose of teacher and student learning.

- Avoiding top-down arrangements in favor of greater mutuality.

- Developing boundary spanning roles that assure continuity and sustain commitment.

- Creating a climate of mutual accountability for all partners.

- Fostering trustworthy relationships between and among all actors.

- Making sound plans for critical support of key resources - fiscal, space and personnel [2].

This project addresses each of these elements. At the outset, both partners identified the common purpose of greater student academic achievement, as measured by EQAO scores ${ }^{1}$, and improved competence and confidence with digital technologies for knowledgebuilding and knowledge-representation. Second, the work was collaboratively designed research by teachers, and university professors as well as principals, teacher candidates and community members. Third, teacher candidates stepped into leadership roles during the pilot year, planning Science Olympics and leaving detailed plans and strategies in place for new candidates, thus indicating a continuity of commitment to the following year's TCs. Fourth, by working with the board and the university's partnership development coordinators and having an oversight committee for the project with members from both communities, we maintained mutual accountability. Through regular informal breakfast meetings, we continued to foster trustworthy relationships with

\footnotetext{
${ }^{1}$ Though neither partner was under any illusions about the many ways in which those data require greater nuance and, accuracy and significance to be relied upon as more than 'public indicators' of student learning.
}

members of the school community. Finally, the school provided a classroom for a university presence in the public school, and the university opened its digital literacy lab to students for coding and gaming camps. All of these elements point to a reciprocal relationship between the partners.

In this paper, we examine the key elements of the first year of this partnership, describing how we envision this work over the next three years. We discuss models for university-school partnerships, the challenges and advantages of these partnerships and the need to design for sustainability. School culture in high needs schools is examined in the context of school leadership, staff turnover and community demographics. Factors that promote school improvement are discussed, as well as the importance of community involvement in student success. Finally, the importance of comprehensive school health as a foundation for school improvement and student achievement is emphasized.

\section{Context of the Partnership}

The partnership in this project involves a Faculty of Education and two high needs elementary schools from one of the local public school boards in walking distance to the Faculty. The purpose of this school improvement project is to design a holistic, technology-enriched approach to the teaching and learning of Literacy and STEM subjects (Science, Technology, Environmental Studies and Mathematics), within the larger context of individual and community health and wellness. Axiomatic to this work is a recognition that healthy children learn better, and healthy schools create stronger communities. The central research questions are:

1) In what ways can a university-school partnership intervention have a significant effect on student achievement in literacy, numeracy and the development of digital literacy? 2)

2) How can a university-school partnership increase the competence and confidence of teachers, teacher candidates and students in digital literacies? And,

3) 3) How can a Comprehensive School Health model be implemented in these schools that positively impact on the physical and mental health and wellbeing of those learning and working there, and identifiably improve students' academic achievement, both measurable and less quantifiable?

As evidenced by the Education Quality and Accountability Office (EQAO) results, these two schools represent significantly underserved populations 
in the Oshawa area. EQAO tests are administered for students in grades three and six. Results of these standardized tests, (while only one measure of learning and achievement), indicate the percentage of students either at or above the provincial standard, which is a level 3 on the provincial achievement charts. According to the provincial results, EQAO scores between 2009-2013 for mathematics dropped from 25$31 \%$ in grade three to $10-18$ percent in grade six. Literacy scores for this same time period indicate 29$37 \%$ of students are at or above the provincial standard. EQAO tests also measure attitudes toward learning, and it is interesting to note that only 31 percent of grade 3 students "liked to read, write or do math most of the time". Researchers in this project are optimistic that these attitudinal measures may be improved by providing greater access to, and expertise in, digital technology for these schools. Evidence from the Fraser Report on Ontario elementary schools [21] indicates that the two schools in this project were rated out of 3013 elementary schools. The first school rated $2723 / 3013$ with a score of $3.7 / 10$. The second school rated 2911/3013 with a score of 2.5/10. This recent evidence (while only one measure of a school's overall quality) demonstrates that both of these schools are facing significant challenges and could benefit significantly from this partnership. Demographic profiles of the economic status of south Oshawa [22] reveal that median income level in 2005 was $\$ 30,393$ per household.

Attentive to both recent findings of sub-par results in mathematics across the province generally, and informed by research findings that identify early mathematics achievement as the primary indicator of subsequent educational success, followed by reading, then by attention skills (Duncan et al, 2007), our research sought a way to support students and their teachers in the areas of mathematics, literacy, science, technology, health and wellness. As a way to begin, teacher candidates (TCs) volunteered their time to help in the target schools on a regular basis, offering workshops, tutoring children, and learning from practicing teachers while promoting literacy, science, math, technology, and environmental studies informed by fundamental principles of mental and physical health sciences and community wellness. To have some validated indicators for identifying impacts, we decided to focus on helping students in ways we hoped would better prepare them for the Educational Quality and Accountability Office math tests Ontario students must take in grades 3 and 6 . Our instructors and teacher candidates worked collaboratively with school staff to try and identify and to assist with the professional development needs of teachers with respect to digital technologies.

\section{Literature Review}

Goodlad has for over twenty years examined the role of university-school partnerships in school reform, and has long emphasized that "missing was the involvement of a university seeking to engage future teachers in school renewal as part of their pre-service education". His comment that the "hard rock issues that must be addressed in the simultaneous renewal of schools and the education of educators", made twenty years ago, speaks to the persisting challenges of making such partnerships sustainable [9]. For Goodlad, elements of an effective partnership model must include the creation of exemplary school sites, the creation of internships and residencies through which future educators may observe and gain experience with the best possible educational practices, the development of curricula that best reflect the best analyses and projection of what young people need, the assurance of equal access by all students to these curricula, the cultivation of site-based development activities designed to foster continual school renewal, and the continuous infusion of knowledge relative to good education in schools and in programs preparing educators.

In a study of a similar partnership between one of the lowest achieving schools in Los Angeles and a university faculty of education, Zetlin and MacLeod agreed that the "technical expertise of the university and the practical understandings of the local educators were equally valued. The university served as a catalyst for change and a source of guidance to the school staff, and together, the school and university actively participated in the conceptualization and implementation of the change effort" [20].

In the ensuing years, these hopes and aspirations for university-school partnerships have not changed. Educators today still believe in the role partnerships can play in both teacher development and school improvement. By many researchers, too, it is currently widely held that, "school-university partnerships hold significant potential to enhance teachers' professional development and thereby foster student learning" [17]. Baker's notes that Goodlad's earlier "visionary perspective is complemented by numerous small scale case studies of a college or university that established a successful partnership with a nearby school district that needed assistance on some aspect of school improvement, in-service teacher training, or strengthening relations" [2].

There is also, though, acknowledgement of the challenges inherent in these partnerships. Schools and universities operate with different tools and audiences, with distinctively different purposes, using sometimes mutually unintelligible discourses, and operating under 
very different governance regulations---so a considerable amount of bridge building is required to enable genuine collaboration. These challenges exist both in Canada and beyond, and are often created by a mismatch of intentions between governments, schools, their policies and pressures for accountability that are often tethered to school improvement plans. References to "the climate of high stakes accountability" have been seen in the [17]. In addition, "schools in the UK, especially in England, have been subjected to high levels of central government intervention" and "governments have tended to incorporate a blend of pressure and support in an attempt to drive up standards of the lowest-attaining schools [16]. Thus, references to measures of accountability such as EQAO and Fraser Institute Reports are but one measure of student achievement and the overall impact of the partnership on student achievement.

At this stage of the project, several challenges persist. Communication between the university research ethics board and the board of education's ethics board took quite some time. Over the first year, we did get ethical approval from both institutions, after much negotiating, however we are still working on a data sharing agreement to enable researchers to look at individual student records. In addition, we see the disparity between school priorities such as "levelled learning interventions" or "reading records" and the university's goals of moving towards "learning in depth" activities [5]. As the project progresses, one of the goals is to merge the school-university cultures more seamlessly, something that Goodlad has historically felt is challenging. He points out that "school systems and universities are not cut from the same cultural cloth. The norms, roles and expectations of educators in each of these educational realms could not be more different". Baker concurs, though many years later, that we need to "seek greater clarity about the complex set of roles and relationships connecting schools and universities". It appears clear that "school culture is one of the most widely cited elements in improving or effective schools. Coherence is a key element in improving schools in economically deprived areas" [16]. One of the challenges going forward will be to continually find such coherence and common ground, as teachers change roles, grade responsibilities, or move to different schools, and as board or district policies change. As it is a common practice to move principals and vice-principals every five years or less, this will also provide a challenge to the sustainability of the project as those in leadership roles move on to new roles or new schools.

The element of leadership is another key component to both school improvement and sustainability of these types of partnerships. Several authors attest to the fact that school leaders play a key role in successful partnerships aimed at school improvement [13][9][16]. Chapman and Harris acknowledge the importance of effective leadership "characterized by the building of leadership teams that motivated, raised morale and sustained performance over time". Muijs et al agree that distributed leadership is an effective means for ensuring that teachers become invested in school improvement and commit to long term school improvement once they are given leadership roles. They state that "it was found that both leadership of the head and teacher involvement were crucial to the success of the programme, the head being more influential on the speed that schools took to implement the reform programme, but teacher commitment being crucial to the quality of implementation" [16]. Both principal leadership and teacher commitment are two important parts of the sustainability of this project. Currently the principal leaders have changed, as is common in elementary schools; however the pilot year investment by the university has resulted in ongoing enthusiasm from both new school leaders.

There are numerous additional factors that are taken to be important supports for school improvement. Moving beyond leadership and school culture, one must consider the role of building a learning community which requires continuous professional development, our model has tremendous potential for meeting this ongoing need for development, in particular with respect to innovative and leading edge uses of technology. Further, there must be efforts made to recruit and retain high quality teachers, high expectations and "value-added curricula, with afterschool programmes, study skills centres and a strong ICT component" [16]. Other authors concur that there is a need for creating a data rich environment within which "schools continuously interrogated existing data to see whether initiatives were working, or whether there are problems with achievement in particular areas or with particular populations". The evidence gleaned from EQAO tests in these two project schools will allow us to use quantitative data to measure if this partnership is indeed having a measurable impact on student success.

Finally, the role of the healthy school must be considered as an important factor in whether a university-school partnership will succeed. Ultimately, a healthy school environment is an element in creating a culture of continuous learning. The critical role of health promotion in school can never be underestimated. Forsberg, the former president of the Canadian Association for Health Physical Education Recreation and Dance (CAHPERD) states,

In almost every single discussion, the recognition of the vital role of physical education in the development of healthy, active 
children was acknowledged. Clearly, schools are seen as the "place" that can have the greatest impact on our children's ability to develop the knowledge, skills, values and habits to be physically active. Children need to be physically educated to be physically active. [7]

In fact, it is perhaps now more than ever that Canadian schools are facing this reality. In a country that is considered with envy by many other nations and rated by the United Nations Human Development Index in 2005 as one of the best places to live in the world, we are experiencing a crisis in health. We are living in an era when our students are becoming less and less fit, cardiovascular disease is on the increase, and stress-related mental health disorders and childhood obesity are approaching epidemic proportions. Paradoxically, this is occurring simultaneously with drastic government cutbacks to its financial support for both health care and education. This short-sighted approach to health promotion in our society should be acknowledged. Healthy children learn best when they are fit and active, and they learn from teachers who are role models. By understanding that we can make an impact at the school level, there is an emphasis on comprehensive school health in this partnership.

Comprehensive approaches to school health can be a critical part of improving high needs schools as well as promoting a healthier university culture. According to Anderson, the Canadian Association for Health, Physical Education and Dance (CAHPERD) defined Comprehensive School Health (CSH) as "a broad spectrum of programs, policies, activities and services that take place in schools and their surrounding communities", He reiterates that school health initiatives have an intimate point-counterpoint relationship with the communities in which they reside. $\mathrm{CSH}$ is a program that is "built from the ground up in four areas: curriculum and integration, social support, support services and the physical environment" [1]. There is a wide body of research indicating the impact that healthy schools and a healthy lifestyle can have on academic achievement. Skevington reports that the World Health Organization (WHO) concurs that "schools are in a position to contribute to social and economic development, increased productivity and a better quality of life for all'[18]. Laforet-Fleisser and Mitchell also note that "even more could be achieved if all schools could promote the healthy development of young people as actively as they promote learning”. [12]

While this paper describes the first year of the partnership, we believe that many of the elements identified in the literature are present in this project in ways that can help us to maintain this university-school initiative for the long term. While these guides have been in the literature for numerous years, few of these studies have indicated a dedicated commitment to technology infused through the partnership. The stakeholders and partners in university-school partnerships must define the unique elements that will be key to fostering success and sustainability in their local communities. Our faculty of education's focus on technology, and the potential impact it can make on mathematics, computational thinking and literacy skills, provides one significant differential that identifies this project as unique and worthy of study. Our goal is to develop and sustain such a partnership that can act as early intervention for local elementary students, to make a long term impact on their academic success and by doing so increase their ability to be successful at post-secondary education.

\section{Theoretical Framework}

Based on the literature review above, there are a myriad of factors which influence the success of a school-university partnership. To analyse these factors over time, an overarching theoretical framework for discussing the elements of this unique partnership is borrowed from Baker's work on the typology of school-university partnerships. Baker identified three typologies for structural configurations of schooluniversity partnerships. The first of these is a "singletier partnership configuration, the most simple and straightforward in which university professors work directly with classroom teachers in the school", The initiative described in this paper moves beyond this level. Baker identifies a second level partnership which he describes as a "multi-tier partnership which is more complex, involves active participation by many actors at various levels of authority and decisionmaking. Professors and teachers are still involved but many others have joined the partnership" [2]. One might classify this project as multi-tier as it does involve both individual classroom initiatives (tutoring) and school wide projects (science Olympics). However, this project falls more clearly in the third level identified by Baker as a "complex brokered partnership configuration, where university leaders go outside their institutions to hire experts who bring their expertise to both university and K-12 educators"[2]. Because we have hired consultants for our coding and gaming camps, and a professor with math expertise from another university to perform a math concert, this partnership falls clearly in Baker's third configuration as a complex brokered partnership. 


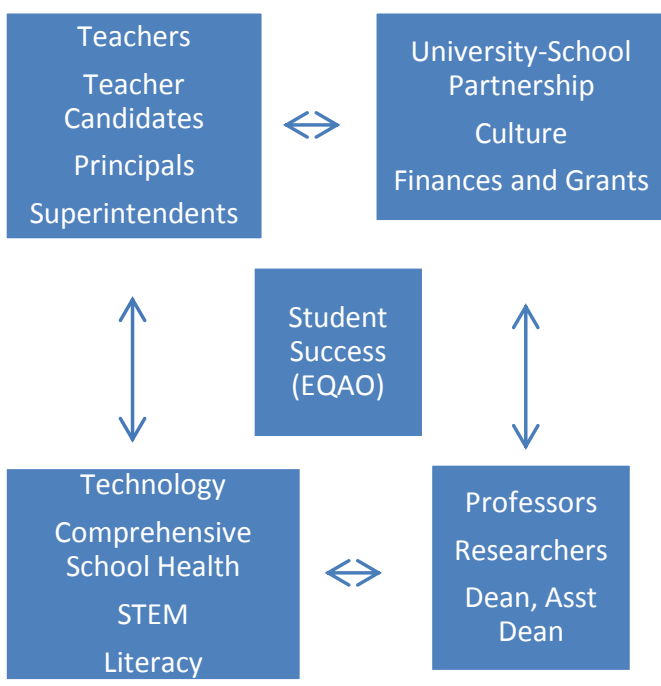

Figure 1: Structural Elements of the UniversitySchool Partnership

Within this configuration, we aim to analyse the partnership using several lenses: structural features, challenges and benefits to these institutions, school culture, leadership and sustainability. Further to this, we insert the factors that can affect school improvement as indicated by the literature and the important roles played by community involvement and comprehensive school health in student success.

\section{Methodology}

This study uses a mixed methods approach to studying both the quantitative EQAO results of grade 3 and grade 6 students and the qualitative aspects of school improvement and teacher development. For the first year, qualitative data was collected using surveys and focus groups. The teacher candidates completed an anonymous online survey to provide feedback on the pilot year of the project as well as having two focus group meetings, one mid-year and one later in the year, to provide data on what was going well and what needed to be improved in the project. Ongoing conversations and meetings with the Partnership Development Coordinator and the board officials (superintendents, principals and vice principals) provided additional data on how to change or modify the project. In addition, the researchers kept field notes related to the activities lead by teacher candidates (Science Olympics plans and activities). We are in the process of pursing a long term data sharing agreement with the board of education to allow us full access to EQAO results for individual students. As we go forward, the methodology in years two and three will include an assessment of grade three and grade six results in mathematics and literacy and use quantitative measures that are publicly accessible to assess academic achievement based on these standardized tests.

Year one, the focus of this year was forging relationships between the teachers, TCs, education faculty and the wider university. Members of the university team visited the schools, identified teacher participants and selected TCs through a formal application and interview process. These TCs were then partnered with a specific teacher and grade for the duration of their year at the faculty of education. TCs observed within the school/classroom extensively prior to assuming their roles as tutors and support teachers in their classes during the second half of the year. The UOIT team, consisting of subject expert instructors, researchers and TCs hosted outreach events in each year. The first large scale event, a math concert (integrating mathematics and the arts) took place early in the year, with all students from both schools attending. A further component, designed to teach programming to elementary students, using the innovative 'coder dojo' model under the design and direction of McMaster University collaborator Brock Dubbels, was offered as a March break camp on site at UOIT. These programs are now spreading at near viral rates as education authorities in Canada and internationally come to recognize that digital literacies must include computational thinking, or they are not truly 'digital' literacies in any full sense. UOIT faculty to introduce a community-building activity involving project participants and parents in the design and creation of a learning garden, which will be chronicled in a written book and through digital story-telling methods as the project progresses. Our aim is to promote increased parental participation -- bearing in mind that the majority of parents are themselves living in poverty, experiencing high rates of unemployment, most have had, themselves, little education, and for most the school is far from being a safe or congenial space - through the creation of a 'learning garden' at both school sites, led by a faculty specialist in science and environmental studies and who has established a research program focused on studying the educational benefits of school gardens. The presumption here is that whereas parents are largely refusing to participate in the academic aspects of their children's schooling, they may feel far more 'at home', welcomed and specifically not so intimidated by joining with their children outside the school building to develop and tend a school garden -- at least there is a better chance of engaging them in this way, and in either case, students gain a hands-on experience of proven value for their learning of both science and literacy as they document in numbers, pictures and in words, the ways their gardens grow. The learning garden has a digital component where project participants use mobile 
technologies to research and digital storytelling to document the design and development of the garden.

Year two, The focus of this year will be "levelling up", both student engagement and teacher knowledge and skills in using digital technology to improve student success. We will continue to provide both schools with volunteer TCs for tutoring, and build on this foundation to offer workshops that support teachers in the project's target curricular areas and enhance integration of technology. These TCs will again be partnered with a specific teacher and grade for the duration of their year at the faculty of education. As TCs demonstrate interest and ability, observation and limited instructional experience in special needs classes will be introduced. TCs will attend their own classes in core methods and classroom management in the UOIT project room within the host school, and those involved in the schools' highest needs classes will be supported by course content focused on designing and implementing educational interventions for special needs students. TCs who prove both interested and computationally capable will also be recruited to carry on the 'coder-dojo' program begun in year one.

Year three, the focus of this year will be integrating TCs into higher needs classes, with particular attention on working one-to-one with individual special education students in areas of need as identified by the principals of the school. We again focus data collection and analytical attention on measuring outcomes for students who are required to take the standardized grade 3 and 6 provincial tests. These TCs will again be partnered with a specific teacher and grade for the duration of their year at the faculty of education. TCs will act as tutors and support teachers in their classes during the second half of the year. TCs will attend their own classes in core methods and classroom management in the host school. In this third year, as well, we will pursue dissemination and outreach activities to extend involvement beyond our pilot university/school collaboration, holding information sessions and workshops to mobilize the knowledge gained through our fully documented pilot project.

Each year, teachers will be invited to the university's digital literacy lab and will bring classes of students to the lab for hands-on experiences with technology, in order to familiarize students with the university, a place in which few would otherwise set foot. Each year we will organize a targeted intervention in the form of a "March Break Camp" for grade six students who will be sitting the EQAO examinations this year will be held at the Faculty of Education's Digital Literacy Research and Development Lab, at which full-day sessions in literacy, mathematics, technology, digital game design, science and art have been designed to give these students a 'leg up' towards higher EQAO scores. To close out each year of our collaboration with these schools, the Faculty will host a summer institute aimed specifically at addressing the professional development needs of the collaborating teachers across our initial 2 project schools.

As the relationships build and strengthen across the Faculty and these two project schools, additional needs will be identified and new program components designed, as we are committed to a reciprocal, respectful, non-intrusive and collaborative process of learning with and from school staff and principals, the best ways to intervene to support our objective: an evidence-based, progressive improvement in academic achievement that impacts significantly on both schools' EQAO scores. To assemble and analyze the extensive data, the faculty's library and information science specialist is developing an education informatics platform for compiling and analyzing data and documentation.

As the project unfolds, we will create short digital documentaries, posted on our project website, to share the experiences of participants. These short documentaries will serve to share the school improvement model that we collaboratively develop, and to highlight the role played by all participants, especially teachers, students, and parents, so as to help re-shape the identity of marginalized schools as agents of change and as leaders in redefining digital literacy to include coding skills. When students are given opportunities to share their personal learning stories with peers, family, teachers and the general public, they are likely to make gains in self-confidence, selfesteem and a sense of community belonging through positive feedback. And, for all participants, Hull \& Katz note "the power of public performance in generating especially intense moments of selfenactment". This identity reshaping of marginalized schools serves our goal of building a sustainable capacity for interrupting the cycle of poverty and underachievement. The documentaries also serve as artefacts and opportunities for collective reflection.

\section{Data Analysis}

Quantitative data analysis will require, in year one, obtaining the prior years' EQAO scores for all students tested to provide a baseline. In all three years of this project, EQAO scores of these same students in grades 3 and 6 will be collected through data sources available at the Durham District School Board, and changes both directly and indirectly related to documented interventions identified. The same process will be used for publically available documentation. School-level objective testing in reading and math will be added to our database as it becomes available. All participants 
will be assigned an anonymized ID code, which will be used to coordinate all available data for that individual. In addition, data will be compiled and analyzed by grade level, and by individual class, for both schools. Indices of academic progress will be compared both over time, and across all Ontario schools, to clearly determine whether and how much student learning outcomes demonstrate statistically significant improvement. Pre- and post-online surveys with teachers and TCs will be analyzed to identify growth in competence and confidence in using digital technology. Regular classroom-based projects will be compiled and analyzed as qualitative indicators of student achievement in the project's targeted curricular foci. Semi-structured interviews conducted with teachers and teacher candidates twice per year will be thematically coded with reference to our specific project goals: increasing student achievement, contributions to professional development, improvements in psychological, behavioural and physical health and wellness, gains student confidence and increases in ability to identify personal educational successes, and any increases in parental involvement.

\section{Discussion}

The first year of this project has been successful on many levels of the complex brokered partnership (Baker, 2010). For purposes of analysis, the elements of the structural framework as indicated in Figure 1 are discussed. The interaction and constant movement of each of these components is important; although individuals in roles may change (teachers, teacher candidates, administrators, and university faculty) the goals of the project remain the same. Thus, sustainability requires us to examine what worked and what needs adjusting from the pilot year. Excellent organizations and entrepreneurs often use this model, whereby they try the original idea, implement it, evaluate and then make directional changes to improve the chances of success of their projects.

First, we have anecdotal evidence from the teachers and teacher candidates of a few changes that needed to be made. Matching the university timetable to the school timetable proved challenging, however we intend to use a cohort model in year two and this has enabled us to creatively timetable students so they can take core courses in the school classroom. By being immersed in the school culture on a more regular basis, the teacher candidates and teachers will benefit from learning together and TCs have a better chance to create meaningful tutoring relationships with students. Teachers, principals and the superintendent feel strongly that this is the best way to have an impact on students' EQAO scores. There is a trend in the research which supports these cohort approaches which "work to change peer cultures at the same time as it supports individuals" [8]. Further, this additional time in schools will support Goodlad's concept of a professional development school:

We had in mind from the beginning that the bumping together of university and school cultures would have a positive effect on both institutions. At the core of this symbiosis was the concept of partner school; a school in which school-based and university-based individuals come together for the simultaneous renewal of both school and the education of educators [9].

Second, there has been a change in the principal and vice-principal roles in one of the schools as well as a new superintendent. To bridge this gap, a meeting has been convened for the new partners to visit the Digital Literacies Research Lab housed at the Faculty of Education and to emphasize the collaborative design of this ongoing partnership. Discussions related to how the technology will be infused throughout the project, while also respecting the board's policies related to technology, will be ongoing. Although there has historically been significant turnover in the school staff, we aim to leverage the power of the university's resources and make the Digital Literacies Lab accessible to teachers, with the hope that this will enable these schools to recruit and retain excellent teachers with a desire for ongoing professional development, particularly with technology.

Third, we continue to apply and reapply for funding that is available from a research perspective and from the teachers themselves through their provincial Ministry of education. Ongoing efforts to bridge the board-university cultures have resulted in other schools becoming interested in the project, so we intend to expand in measured steps, what is referred to by Chapman and Harris as the fact that "a clear focus on a limited number of goals has also been identified as an important contributory factor to effective and improving schools"

Fourth, the Dean, Associate Dean and Professors involved in this project remain the same, and this should provide some elements of stability to the project. There is an intention to invite greater involvement of our math and science teachers to emphasize the STEM focus and enable more teacher candidates with these specializations to be participating in the project. We continue to pursue data sharing agreements with the board and this will enable us to measure quantitative EQAO results in future.

Fifth, the activities that were run in the first year of the project included a math concert, March break 
coding camp, summer technology camp, Science Olympics and more. A teacher candidate from the pilot year has volunteered to be a mentor to the incoming candidates, and so the knowledge transfer for organizing these events should be seamless. However, we also aim to empower the new teacher candidates to integrate their own ideas to the project. In particular, a greater emphasis on developing healthy school activities will be included, including a more regular volunteer cadre of teacher candidates at the school's breakfast program and in leading extracurricular activities that inspire healthy active living.

Finally, the emphasis on technology will continue to be an important element in the project. The university Digital Literacies Research Lab will be incorporated on a more regular basis, allowing teachers and their students from the partner schools to visit the university. Research shows us that "physically experiencing a university through a schedule of site visits designed to familiarise young people has proven effective in cases where young people would otherwise be unlikely to visit a university, such opportunities can be significant in debunking fears and also in awakening a desire to attend" [8]. By bringing students to the university, we also aim to set and maintain high expectations. Some authors claim that "pupils from low SES backgrounds are often more capable of higher order thinking than is often supposed and should be exposed to curriculum that is as rich as that of their advantaged counterparts, built around powerful ideas and focussing on metacognitive skills"[16]. Raising expectations of the students, their teachers and the school community is a key goal of this project and a significant element in bridging the digital divide.

\section{Conclusions and Future Directions}

The first year of this project has presented many opportunities and challenges. An online survey of the 30 teacher candidates at the end of the year showed that many teacher candidates felt that this was a productive initiative in terms of giving them greater school-based experience in their pre-service year. However, they also indicated that greater cohesiveness between the school timetable and their own would facilitate their presence in the high needs schools on a more regular basis. Additional data from teacher candidate focus group discussions indicated that the Faculty of Education timetable had to be revised in order to facilitate their presence in the schools. Going forward, we have secured an elementary classroom in the host school that will be the site for Core Methods and Language Arts courses for our teacher candidates. Our intent is to populate the room with technology that the school might not otherwise afford. Teacher candidates will become the leaders and teachers for digital literacy and so we predict that many benefits to learners will occur. The lessons learned when immersed in the school culture will allow teacher candidates to make a better match of theory and practice. Classroom teachers will have access to university labs for themselves and their students.

Future elements of this partnership will include expansion to the secondary school level. Several of the investigators have secondary teaching experience, and two of the teachers have been graduate students at the university, one wanting to pursue doctoral work. Currently the project has had several inquiries by other schools. A preliminary meeting with the teachers and administrators has indicated that future directions may include coding and math camps for grade nine students, as well as digital gaming camps. In addition, greater emphasis on the role of healthy schools, will involve support for teachers to model health-related attitudes, behaviours and choices as they are role models for their students and key players in transforming the school culture.

The leveraging of the technology available at the host university has a significant impact in helping make these changes to local high needs schools. However, in creating a professional learning community, it is important to note the benefits to both partners. University professors who would not otherwise be in school environments on a regular basis may gain new and greater perspectives on theory to practice connections. A deeper understanding of the reality of a living school culture can help to inform university professors about the pedagogy that exists in the partner schools. With the common goal of student success, the professional learning community provides rich learning experiences for everyone who embraces it. This is what Goodlad refers to as "an ethic of collaboration and collaborative inquiry and action, more than anything else, that characterizes, or ought to characterize the processes that go on in a schooluniversity partnership"[9]. Most importantly, the collaborative experience of board administrators, teachers, and university faculty will level the playing field and create a lasting foundation; this bridge between two very different educational cultures will most certainly impact the social equity for students in our local community. Through the Faculty's technology-focused graduate programs, the university provides readily accessible professional development opportunities in building requisite technological skills and pedagogical content knowledge to support 21st century learners, no matter what their family's education or income levels. This is something a faculty of education ought to be able to accomplish; this persistent pattern whereby the greatest predictor of educational success is material wealth remains a shameful testimony to the consequences of leaving 
high needs schools to solve problems of social inequality on their own. We can, and we should, do better than this, and this project provides a researchbased model of how building these bridges can make a difference.

\section{References}

[1] Anderson, A. (2002). Using comprehensive approaches to health to make schools smarter, stronger and safer. Physical and Health Education Journal, 68(4), 14-20.

[2] Baker, P.(2011). Three configurations of schooluniversity partnerships: an exploratory survey. Planning and Changing, 42(1/2) 41-62.3.

[3] Chapman, C. \& Harris, A. (2010). Improving schools in difficult and challenging contexts: strategies for improvement. Educational Research, 46(3), 219-228. DOI: 10.1080/0013188042000277296.

[4] Duncan, G. J., Dowsett, C. J., Claessens, A., Magnuson, K., 6.Huston, A. C.; Klebanov, P., Pagani, L.S., Feinstein, L., Engel, M., Brooks-Gunn, J., Sexton, H.,Duckworth, K. \& Japel, C. (2007) School readiness and later achievement. Developmental Psychology, 43(6), Nov 2007, 1428-1446.

[5] Egan, Kieran (2009). Learning in depth. Engaging the whole child: Reflections on lies. 133-142.

[6] Ertmer, P. \& Hruskocy, C.(1999). Impacts of a university-elementary school partnership designed to support technology integration. Education Technology Research and Development,47(1) 81-95.

[7] Forsberg, N. (2002). Physical education: reclaiming the foundation. Physical and Health Education Journal, 68(3), 23.

[8] Gale, T., Sellar, S., Parker, S., Hattam, R., Comber, B., Tranter, D. \& Bills, D. (2010). Interventions early in school as a means to improve higher education outcomes for disadvantaged (particularly low SES) students, National Centre Student Equity in Higher Education, Underdale, S. Australia. http://hdl.handle.net/10536/DRO/DU:30040776

[9] Goodlad, J. (1993) School-university partnerships and partner schools. Educational Policy 7(24) DOI: 10.1177/089504893007001003. Sag Publications.

[10] Guertin, M. (2007). An examination of the effect of a comprehensive school health model on academic achievement: The effect of Living School on EQAO test scores. Toronto (ON): Ontario Institute for Studies in Education, University of Toronto.

[11] Helfeldt, J., Capraro, R., Capraro, M., Foster, e. \& Carter, N. (2009). An urban schools-university partnership that prepares and retains quality teachers for "high need" schools. The Teacher Educator, 44(1), 1020. DOI 10.1080/08878730802520050.

[12] Laforet-Fliesser, Y. \& Mitchel, I. (2002). Healthy school communities: collaborative approaches that work. Physical and Health Ed Journal, 68(2),12-18.

[13] Leithwood, K., Jantzi, D. \& McElheron-Hopkins, C. (2007). The development and testing of a school improvement model. School Effectiveness and School Improvement: An International Journal of Research, Policy and Practice. 17(4) 441-464.
[14] Leithwood, K. \& Steinbach, R. (2002). Successful leadership for especially challenging schools. Journal of Leadership in Education, 79(2) 73-82.

[15] McDougall, D., Gaskell, J., Flessa, J., Kugler, J., Jang, E., Herbert, M., Pollon, D., Russell, P., \& Fantilli, R. (2006). Improving student achievement in schools facing challenging circumstances. Literacy and Numeracy Secretariat Draft Report. OISE University of Toronto.

[16] Muijs, D., Haris, A., Chapman, C., Stoll, L. \& russ, J. (2004). Improving schools in socioeconomically disadvantaged areas: A review of research evidence. School Effectiveness and School Improvement 15(2) 149-175.

[17].Scribner-Bartholomew, S. \& Haymore-Sandholtz, J. (2009). Competing views of teaching in a school-university partnership. Teaching and Teacher Education, 25(2009) 155165.

[18].Skevington, S. (Ed.). (2002). World Health Organization Information Series on School Health. Health Promoting Schools. Geneva, Switzerland.

[19] Smith, D. (1992). Sociology from women's experience: a reaffirmation. Sociological Theory, 10(1), 88-98.

[20] Zetlin, A. \& Macleod, E. (1995). A school-university partnership working toward the restructure of an urban school and community. Education and Urban Society, 27(411). DOI: $10.1177 / 0013124595027004004$

[21] Fraser Institute (2014) "Ontario Elementary School Rankings 2014"; https://www.fraserinstitute.org/uploadedFiles/fraserca/Content/researchnews/research/publications/ontario-elementary-schoolrankings-2014.pdf

[22] City Data (2005) "Income Rankings in Oshawa City"; http://www.city-data.com/canada/Oshawa-City.html 